\title{
CULTURA VS. ESTADO: RELAÇÕES DE PODER NA EDUCAÇÃO ESCOLAR INDÍGENA
}

\section{CULTURE VS. STATE: POWER RELATIONS IN BRAZILIAN INDIGENOUS EDUCATION}

\section{Carlos Maroto Guerola*}

À memória de Marcondes Namblá (1979 - 2018)

\section{RESUMO}

Com base numa pesquisa etnográfica, busca-se neste trabalho analisar estratégias de construção de sentido que comunidades indígenas (particularmente a comunidade LaklãnõXokleng da TI Ibirama Laklãnõ) e o Estado brasileiro (particularmente o Estado de Santa Catarina) empregam no intuito de perpetuar ou transformar as relações de poder estabelecidas entre eles, particularmente no contexto da educação escolar. Por meio da análise de uma interação ocorrida, no âmbito de um programa de formação continuada, entre professores, lideranças e anciões indígenas e uma gestora da instituição diretamente responsável pelas escolas Laklãnõ-Xokleng na rede estadual de educação em que se inserem, são elencadas e ilustradas estratégias que dizem respeito aos seguintes fenômenos: 1) o sobrecarregamento de palavras e formas que diferentes instituições e os seus centros de transmissão de poder fazem estrategicamente com as suas próprias intenções no intuito de espoliar as "possibilidades intencionais da língua" (BAKHTIN, 2002, p. 97); 2) a remissão por esses centros de transmissão de poder a gêneros do discurso específicos para determinarem ou satisfazerem regras e exigências "complexas e pesadas" (FOUCAULT, 2004b, p. 13) para a enunciação de certos discursos de forma eficaz e coercitiva; e 3) a consciência da própria capacidade de transformação de seres humanos que, exercendo seu poder, fazem culturas (FREIRE, 1967) ou, pelo contrário, a abdicação dessa consciência por parte de seres humanos que incorporam estados em processos de acomodação/ajustamento por meio dos quais acabam se sentindo (ou se fingindo) impotentes e paralisados e negando a natureza performática das instituições (BUTLER, 2010). As estratégias de construção de sentido identificadas, em virtude da sua natureza linguística, ideológica e política, assim como em virtude da intencionalidade e sistematicidade que as permeiam, constituem em si mesmas políticas linguísticas, em estreita ligação com políticas de identidade.

Palavras-chave: poder; educação escolar; Laklãnõ-Xokleng.

\section{ABSTRACT}

Upon an ethnographic research, this paper aims at analyzing meaning-construction strategies deployed by Native Brazilian communities (the Laklãnõ-Xokleng community from the Ibirama Laklãnõ indigenous land particularly) and the Brazilian State (namely the State of Santa Catarina) to perpetuate or to transform power relations established between them within the context of school education. By means of the analysis of an interaction

\footnotetext{
* Universidade da Integração Internacional da Lusofonia Afro-brasileira (UNILAB), Campus dos Malês, São Francisco do Conde (BA), Brasil. cmguerola@gmail.com
} 
that took place within an in-service teacher training program among Laklãnõ-Xokleng teachers, chiefs and elderly and an official from the institution directly in charge of the Laklãnõ-Xokleng schools within the state's education system in which they are embedded, strategies are raised and illustrated concerning the following phenomena: 1) the way words and forms are strategically overcharged by competing institutions with their own intentions to despoil the intentional possibilities of language (BAKHTIN, 2002); 2) the referral to specific discursive genres to determine or fulfill tough rules and demands (FOUCAULT, 2004b) to make the enunciation of certain discourses effective and coercive; and 3) the awareness of one's own capacity of transformation of human beings who, by exerting their power, make cultures (FREIRE, 1967) or, on the contrary, the abdication from that awareness by well-off adjusted human beings that embody states and end up feeling themselves (or feigning to feel) powerless and paralyzed, and denying the performative nature of institutions (BUTLER, 2010). The meaning-construction strategies identified, because of their linguistic, ideological and political nature and because of being willful and systematic, make up linguistic policies themselves, closely tied to identity policies.

Keywords: power, indigenous schooling; Laklãnõ-Xokleng.

\section{INTRODUÇÃO}

Em decorrência da convivência e percurso etnográfico ao longo de sete anos em contextos escolares e de formação de professores no universo indígena de Santa Catarina, ao me deparar com a proposta deste dossiê, qual seja, abordar "políticas linguísticas em sua relação com políticas de identidade de modo a emprestar visibilidade, particularmente, a questões que afligem as populações indígenas na contemporaneidade e às estratégias que elas empregam para fazerem frente às posições de subalternidade em que frequentemente são colocadas" (ver Introdução a este volume), logo enxerguei a possibilidade de tentar contribuir para a questão focalizando a perpétua dissimetria (FOUCAULT, 2004a) que caracteriza as relações de poder entre os povos indígenas e o Estado brasileiro.

É possível afirmar, a respeito de todos os contextos indígenas no Brasil, que essa perpétua dissimetria (e as consequências que ela acarreta) é uma das questões que têm afligido as populações indígenas de forma mais direta tanto ao longo da história quanto atualmente, e que ela tem reflexos também (antes, é particularmente visível) no contexto da educação escolar. De fato, apesar de garantida enquanto direito pela legislação brasileira', as relações dissimétricas de poder entre o Estado

1. O direito indígena a uma educação escolar diferenciada encontra o seu fundamento jurídico no artigo 210 da Constituição Federal de 1988, o qual assegurou às comunidades indígenas "a utilização de suas línguas maternas e processos próprios de aprendizagem" (BRASIL, 1988, s/p.) no âmbito do ensino fundamental regular. Convidamos os leitores e as leitoras deste artigo à consulta dos principais documentos norteadores da educação escolar indígena diferenciada no Brasil no cap. 5 da coletânea de legislação indigenista de Magalhães (2005). 
e as comunidades indígenas obstaculizam (quando não impossibilitam) a efetivação de uma educação diferenciada nas escolas indígenas².

$\mathrm{Na}$ minha pesquisa de doutorado (GUEROLA, 2017b) ${ }^{3}$, foi-me possível registrar enunciados - isto é, conjuntos coerentes de signos que conformam unidades de sentido, conforme definidos por Bakhtin $(1997,2006)$ - em encontros/ confrontos entre os participantes de um programa de formação continuada para professores indígenas ${ }^{4}$ e gerentes e técnicos de instituições governamentais responsáveis pelas suas escolas. A partir da análise desses enunciados, é possível perceber estratégias de construção de sentido por meio das quais indivíduos que são centros de transmissão de poder de comunidades indígenas e/ou do Estado buscam transformar ou perpetuar as dissimétricas relações de força estabelecidas entre eles no contexto da educação escolar. Defendo neste trabalho que essas estratégias de construção de sentido, pela sua natureza política e ideológica, e pela intencionalidade e sistematicidade que as permeiam, configuram políticas, que são linguísticas e estão estreitamente vinculadas à incorporação de instituições enquanto (id) entidades.

No intuito de emprestar visibilidade a essas políticas linguísticas e à incorporação dessas (id)entidades institucionais, trago aqui um recorte dos dados analisados em Guerola (2017b), especificamente uma interação ocorrida entre professores, sábios e lideranças da Terra Indígena (TI) Ibirama Laklãnõ ${ }^{5}$ e uma gestora da instância institucional diretamente responsável pelas escolas dessa TI. Buscarei, com base na análise desse recorte, dar resposta à seguinte pergunta: Que estratégias de construção de sentido membros da comunidade Laklãnõ-Xokleng da TI Ibirama Laklãnõ e membros do Estado de Santa Catarina empregam no intuito de perpetuar/transformar as relações de poder estabelecidas entre eles, especificamente no contexto da educação escolar?

2. Para Brighenti e Nötzold (2010), as escolas indígenas hoje se encontram extraordinariamente distantes daquilo que as comunidades têm demandado ao longo das últimas décadas, não tendo quase permitido a incorporação dos saberes e práticas tradicionais no seu bojo. Para uma retrospectiva geral da educação escolar indígena diferenciada no Brasil, cf. Souza (2009).

3. Desenvolvida etnograficamente com base nas orientações de Clifford e Marcus (1986), Erickson (1990), Hymes (1996) e Davies (1999), dentre outros.

4. Particularmente, o programa Ação Saberes Indígenas na Escola, criado em 2013 pela Secretaria de Educação Continuada, Alfabetização, Diversidade e Inclusão (SECADI) do Ministério da Educação do Governo Federal brasileiro e implementado em Santa Catarina junto às comunidades Guarani, Kaingang e Laklãnõ-Xokleng pela universidade federal desse estado (UFSC).

5. Localizada no Alto Vale do Itajaí, com 14.084 ha, a TI Ibirama Laklãnõ, criada originalmente como Reserva Indígena Duque de Caxias em 1926, foi a única terra indígena Laklãnõ-Xokleng até a demarcação, em 2000, da TI Rio dos Pardos, de 758 ha, no município de Porto União (SC). 


\section{FUNDAMENTAÇÃO HISTÓRICA E TEÓRICA}

Pelos seus mecanismos e estratégias nunca terem sido muito estudados na tradição científica ocidental, o poder é, na visão de Foucault (1979), um grande desconhecido. Não é difícil concordar com essa afirmação quando se repara na inexistência de estudos a respeito de relações de poder no âmbito da educação escolar indígena contemporânea no Brasil, o que não é diferente na área de Linguística Aplicada (LA) ${ }^{6}$. Essa inexistência não deixa de ser paradoxal se atentarmos para o fato de que a quem cabe o dever de garantir o direito à educação das populações indígenas (ou, antes, como sempre frisado pelos indígenas, à educação escolar) é ao Estado ${ }^{7}$, uma instituição tradicionalmente avessa a essas populações. Vale como exemplo disso o financiamento, ao longo de todo o século XIX e dos primeiros anos do século XX, por parte do Governo da Província de Santa Catarina, de campanhas para o extermínio dos Laklãnõ-Xokleng, executadas por organizações como a companbia de pedestres, os batedores do mato ou os bugreiros (WITTMANN, 2005). Essas campanhas resultaram na quase total extinção desse povo, que ficou reduzido a 400 indivíduos na primeira década do século XX, e a apenas 150 na década de 1930 devido às epidemias advindas do contato direto com o branco após a pacificação de 1914 (WITTMANN, 2005; WIIK, 1998).

Após esse ano, o Estado brasileiro buscou confinar os Laklãnõ-Xokleng dentro dos limites de uma única reserva indígena, a Reserva Indígena Duque de Caxias, sob tutela do Serviço de Proteção ao Índio (SPI), instituição indigenista de atitudes e práticas mais que controversas (SANTOS, 1978; WITTMANN, 2005). Além disso, através do Departamento Nacional de Obras e Saneamento (DNOS) e graças à displicência da instituição em que o governo militar transformou o SPI - a Fundação Nacional do Índio, FUNAI, a partir de 1967 -, o Estado deu início, em 1972, à construção de uma barragem de contenção de cheias na área central e mais produtiva dessa única reserva indígena. $\mathrm{O}$ Estado não previu à época qualquer indenização aos índios, nem trabalhos para prepará-los para as mudanças que iriam ocorrer, como a inundação das suas roças e a destruição das suas casas (SANTOS,

6. Um estado da arte preliminar do trabalho da LA em contextos indígenas durante as duas primeiras décadas do século XXI encontra-se disponível em Guerola (2017b). Remeto à Cavalcanti (1999) para um estado da arte, a respeito da década de 1990, dos estudos sobre educação escolar em contextos bilíngues (principalmente indígenas, mas também de imigração, de fronteira e de surdez).

7. Por disposição constitucional, a educação, "direito de todos", é "dever do Estado e da família". Para garantia de tal direito, "a União, os Estados, o Distrito Federal e os Municípios organizarão em regime de colaboração seus sistemas de ensino", os Municípios atuando "prioritariamente no ensino fundamental e na educação infantil", e os Estados e o Distrito Federal "prioritariamente no ensino fundamental e médio" (BRASIL, 1988, s/p.). 
1987). Dentre muitos outros, esses foram apenas alguns dos efeitos devastadores de um "etnocídio" (SANTOS, 1987, p. 46) cujas consequências são vivenciadas e denunciadas pelos Laklãnõ-Xokleng até hoje ${ }^{8}$.

Haja vista a aberrante violência que tem caracterizado historicamente a relação de poder entre o Estado brasileiro e o Povo Laklãnõ-Xokleng, não é possível se furtar de afirmar, com base em Foucault (1979, p. 99), que as relações de poder atuais entre essas instituições têm por base uma relação de força "estabelecida, em um momento historicamente determinável, na guerra e pela guerra". Para esse filósofo, a configuração do poder político deriva de guerras, cujo fim, todavia, não suspende os efeitos das mesmas nem neutraliza "os desequilíbrios que se manifestaram na batalha final" (FOUCAULT, 1979, p. 99). Tais desequilíbrios continuam caracterizando as relações de poder nas instituições que comandam a "paz civil" de uma dada sociedade, assim como as desigualdades econômicas da mesma e a linguagem e o corpo dos indivíduos que fazem parte dela (FOUCAULT, 1979, p. 99). Cientes, portanto, da origem bélica das relações de poder em âmbitos institucionais, como a educação escolar Laklãnõ-Xokleng em Santa Catarina, podemos agora refletir sobre o que é o poder e quem o exerce.

Foucault (1979, p. 45) defende que o poder não seja entendido como um "fenômeno de dominação maciço e homogêneo" de indivíduos, grupos ou classes que deteriam o poder sobre outros que não o possuiriam e estariam a ele submetidos. O poder, segundo esse autor, deve ser entendido enquanto fluxo, enquanto "algo que circula, ou melhor, como algo que só funciona em cadeia": o poder constitui os indivíduos e passa por eles, sendo por eles exercido nas redes e malhas onde eles circulam e onde, constituindo os seus centros de transmissão, estão sempre em posição de exercê-lo e/ou sofrer a sua ação (FOUCAULT, 1979, p. 103).

Certamente, se o poder se exerce é porque ele é ação: ele é, acima de tudo, um "modo de ação de alguns sobre outros", ou, antes, um modo de ação sobre as ações dos outros (FOUCAULT, 1995, p. 242). Agindo sobre as ações dos outros, os indivíduos operam "sobre o campo de possibilidade onde se inscreve o comportamento dos sujeitos ativos" (FOUCAULT, 1995, p. 243), conduzindo as suas condutas "num campo mais ou menos aberto de possibilidades" e ordenando a probabilidade da sua materialização. É por isso que o corpo, enquanto realidade biopolítica (FOUCAULT, 1979), assume um lugar central nas relações e mecanismos de poder, pois, se o exercício do poder consiste em agir sobre as possibilidades de

8. Cf. ENCHENTE - O outro lado da Barragem Norte. Direção de Humberto Capucci. 2017. Disponível em: < https://www.youtube.com/watch?v=kTKNmogdQAY $>$. Acesso em: 05 out. 2018. 
ação dos outros e é através do corpo que agimos, nada é, portanto, "mais material, nada é mais físico, mais corporal que o exercício do poder" (FOUCAULT, 1979, p. 84).

A noção de poder de Foucault implica liberdade, pois, se é possível ordenar a probabilidade das ações dos corpos dos outros, é porque esses outros são livres, isto é, "sujeitos individuais ou coletivos que têm diante de si um campo de possibilidade onde diversas condutas, diversas reações e diversos modos de comportamento podem acontecer" (FOUCAULT, 1995, p. 244). Assim, "se há relações de poder em todo o campo social, é porque há liberdade por todo lado", conclui Foucault (2004a, p. 277). Sempre há liberdade para a insubmissão, para fugas, subterfúgios ou resistência violenta ${ }^{9}$ (FOUCAULT, 1995): aqueles que reconhecem o poder que se exerce contra eles como abuso podem acionar a sua insubmissão "onde se encontram e a partir de sua atividade (ou passividade) própria" (FOUCAULT, 1979, p. 46).

Nesse sentido, o pensamento de Foucault vai ao encontro da visão de Giddens (1984), para quem os seres humanos são agentes propositados que exercem poder, produzem efeitos e podem, perante uma determinada situação, se comportar de formas diferentes. Para Giddens (1984, p. 14), o poder diz respeito a "intervir no mundo ou abster-se de tal intervenção, com o efeito de influenciar um processo específico" e "fazer a diferença" num curso de eventos pré-existente. Essa visão é, por sua vez, condizente com a visão de Freire $(1967$, p. 41), para quem, pelo fato de existir, "o homem pode ser eminentemente interferidor":

A partir das relações do homem com a realidade, resultantes de estar com ela e de estar nela, pelos atos de criação, recriação e decisão, vai ele dinamizando o seu mundo. Vai dominando a realidade. Vai humanizando-a. Vai acrescentando a ela algo de que ele mesmo é o fazedor. Vai temporalizando os espaços geográficos. Faz cultura. (FREIRE, 1967, p. 43)

Criando e decidindo, exercendo poder e produzindo efeitos através das suas ações, os homens dominam, dinamizam e humanizam a realidade, fazendo, dessa feita, cultura. Em linha com essa compreensão de cultura como algo que se faz, Heath e Street (2008) defendem a idoneidade de entender cultura não como substantivo e sim como verbo, o que, para Van Maanen (1988), faz jus em maior medida ao seu caráter dinâmico e em constante transformação.

9. Para um estudo aprofundado da forma em que os Laklãnõ-Xokleng têm materializado essas formas de resistência violenta, fuga ou subterfúgios ao longo do histórico do seu contato com o homem branco, cf., dentre outros, Lavina (1994), Santos (1997), Loch (2004), Wittmann (2005), Wiik (2010) e Guerola (2017b) 
O poder dos agentes propositados e interferidores que fazem cultura pode ser, contudo, minado. Nesse sentido, Freire (1967, p. 42-43) observa que a "acomodação" e o "ajustamento" fazem com que homens e mulheres sacrifiquem a sua capacidade de criação e decisão e comecem a se sentir "esmagado[s] por um profundo sentimento de impotência" e paralisados em relação às "catástrofes que se avizinham". Segundo o pedagogo pernambucano, através desse processo de acomodação e ajustamento, homens e mulheres abdicam da consciência da sua capacidade transformadora, tornando-se meros espectadores, "tragicamente assustado[s]" e em dúvida em relação "à sua possibilidade" (FREIRE, 1967, p. 4344). Para Freire (1967, p. 43), essa é "uma das grandes, se não a maior, tragédia do homem moderno".

Associo aqui as reflexões de Freire (1967) quanto à acomodação e ajustamento de seres humanos com a chamada de atenção que Butler (2010) faz em relação à performatividade das instituições. Segundo essa autora, instituições são construídas por meio do exercício do poder de seres humanos: a criação, perpetuação, transformação e destruição daquelas dependem da intervenção destes. Porém, segundo essa autora, muito frequentemente, indivíduos assumem e naturalizam que instituições existem autonomamente e operam independentemente, à margem do poder e da agência dos indivíduos que as incorporam e materializam.

Além de a fenômenos performáticos, as instituições podem ser reduzidas, em última análise, a fenômenos eminentemente discursivos (HARVEY, 1996). É por isso que o fato de assumirmos discursivamente a autonomia das instituições acaba influenciando determinantemente no modo em que elas parecem ser e no modo em que pensamos que elas são de fato ${ }^{10}$ (BUTLER, 2010) - assim como no modo em que falamos delas quando as incorporamos enquanto (id)entidades. A performatização de instituições é atrelada neste trabalho à performatização de identidades por esta última ser compreendida analogamente enquanto fenômeno discursivo e "sociohistórico por natureza", e, por isso mesmo, enquanto fenômeno essencialmente político e ideológico (MAHER, 1998, p. 117).

Nesse quadro, ao performatizar certas identidades institucionais, seres ajustados e acomodados falam a respeito de instituições como se fossem entidades com existência própria em relação às quais a sua agência é inócua. Essa política linguística de identidade contribui para o fortalecimento da suposta autonomia e vida própria das instituições, reificando-as e, simultaneamente, deificando-as. É

10. Pensemos, por exemplo, em como se fala na atualidade a respeito das 'regras' ou 'exigências' do mercado ou do sistema, como se essas instituições tivessem existência e desejos próprios, independentes dos agentes propositados que as constroem. 
nesse sentido que sobrecarrego neste trabalho o signo incorporação com a intenção de ele fazer referência à estratégia de construção de sentido de agentes propositados que performativizam instituições enquanto (id)entidades com existência própria. Segundo Butler (2010, p. 148, grifo meu), reconhecer a performatividade e a natureza eminentemente discursiva das instituições faz com que, em última instância, "a própria existência desses entes possa ser colocada em dúvida" - donde a coerência de representar instituições enquanto (id)entidades que sujeitos incorporam, como ocorre, por exemplo, em cerimônias e rituais religiosos. A noção de performatividade das instituições de Butler (2010, p. 147), aqui associada à incorporação de (id)entidades, busca, assim, "rebater uma certa presunção metafísica a respeito de categorias culturalmente construídas e levar a nossa atenção aos diversos mecanismos dessa construção".

A performatização de instituições enquanto (id)entidades pode ser associada não só a processos de acomodação e ajustamento, mas também às guerras silenciosas que dão sequência às guerras físicas e perpetuam "estados de dominação" nas instituições. Esses estados de dominação se caracterizam por relações de poder "perpetuamente dissimétricas" (FOUCAULT, 2004a, p. 277), em decorrência das quais certos indivíduos e grupos têm sua margem de liberdade severa e perpetuamente restrita.

Em linha com a sua visão de poder, Foucault (1979, p. 102) convida a não entendermos dominação enquanto

dominação global de uns sobre os outros, mas [enquanto] as múltiplas formas de dominação que podem se exercer na sociedade. Portanto, não o rei em sua posição central, mas os súditos em suas relações recíprocas: não a soberania em seu edifício único, mas as múltiplas sujeições que existem e funcionam no interior do corpo social.

É por isso que, para Foucault $(1995$, p. 234), as lutas e confrontos em torno do poder se materializam contra o "inimigo imediato", isto é, as instâncias de poder mais próximas que exercem mais diretamente sua ação sobre os indivíduos. Com base nessa asserção, Foucault (1979, p. 102) recomenda que os pesquisadores envolvidos no estudo do poder o estudemos em suas ramificações, "na extremidade cada vez menos jurídica de seu exercício", isto é, nas instituições locais "onde ele se implanta e produz efeitos reais". Seguindo essa orientação, a relação de poder perpetuamente dissimétrica entre o Estado de Santa Catarina e o Povo LaklãnõXokleng será estudada neste trabalho no âmbito das sujeições entre súditos que constituem centros de transmissão de poder em ramificações institucionais imediatamente inimigas - as escolas indígenas da TI Ibirama Laklãnõ e a instância governamental diretamente responsável por elas. 
É relevante igualmente que, para Foucault (1995, p. 235), as lutas em torno do poder dizem respeito "aos efeitos de poder relacionados ao saber, à competência e à qualificação" e, portanto, a "privilégios do saber". Nesse sentido, pelo discurso não ser "simplesmente aquilo que traduz as lutas ou os sistemas de dominação, mas aquilo por que, pelo que se luta, o poder do qual nos queremos apoderar" (FOUCAULT, 2004b, p. 5), grupos privilegiados pela dissimetria de certas relações de poder impõem seus "privilégios do saber" no discurso.

Com base nesses "privilégios do saber", a enunciação nos moldes de "tipos relativamente estáveis de enunciados" ou "gêneros do discurso" é exigida em certas "esferas de utilização da língua" (BAKHTIN, 1997, p. 279) como, por exemplo, as instituições. Desse modo, são estabelecidas regras e exigências "complexas e pesadas" (FOUCAULT, 2004b, p. 13), em relação ao possível "conteúdo temático", "estilo verbal" e "construção composicional" (BAKHTIN, 1997, p. 279) dos enunciados, que devem ser obedecidas para que os mesmos possam ter "eficácia", "efeito sobre aqueles aos quais se dirigem" e "valor de coerção" (FOUCAULT, 2004b, p. 15) no âmbito de determinadas instituições ${ }^{11}$. Nesse sentido, regras e exigências quanto ao possível conteúdo, estilo e estrutura dos enunciados acarretam a espoliação de "possibilidades intencionais da língua" (BAKHTIN, 2002, p. 97), graças à qual grupos com privilégios de saber sobrecarregam "palavras e formas com suas próprias intenções", tornando-as alheias a "outras correntes, partidos, obras e pessoas" (BAKHTIN, 2002, p. 97).

É a partir dessas palavras e formas espoliadas, contudo, que centros de transmissão de poder, atores e construtores sociais "estrategistas", produtores e interpretadores, mobilizam estratégias para a construção de sentidos $(\mathrm{KOCH}$, 2011, p. 19) nas lutas em torno do poder que têm lugar nas instituições.

Que estratégias de construção de sentido membros da comunidade LaklãnõXokleng da TI Ibirama Laklãnõ e membros do Estado de Santa Catarina mobilizam no intuito de perpetuar ou transformar as relações de poder estabelecidas entre eles no contexto da educação escolar? Com base nas ferramentas conceituais apresentadas nesta fundamentação teórica, à que dou fim, dou resposta a essa pergunta na seção a seguir.

11. Pensemos, a modo de exemplo, no âmbito institucional da universidade e nas regras complexas quanto a conteúdo, estrutura e estilo que um doutorando deve obedecer na enunciação da sua tese para que ela tenha eficácia e valor de coerção de modo a ser aprovada pela banca na sua defesa, ou aquelas que um candidato deve obedecer para que as suas provas sejam bem avaliadas pela banca de um concurso, ou aquelas que um pesquisador deve obedecer para que os seus artigos sejam aceitos para publicação em revistas especializadas, etc. 


\section{ANÁLISE DE DADOS}

O dado aqui analisado consiste na transcrição do registro audiovisual da interação mantida, na manhã do dia 14 de agosto de 2015, na abertura do I Grande Encontro Laklãnõ-Xokleng da Ação Saberes Indígenas na Escola (ASIE) em Santa Catarina, entre professores, sábios e lideranças da TI Ibirama Laklãnõ e a gerente da instância governamental diretamente responsável pelas escolas das comunidades dessa etnia. ${ }^{12}$

As atividades de formação continuada da ASIE, conforme implementada em Santa Catarina pelo Núcleo UFSC, dividiram-se em grandes encontros e ações. Nos grandes encontros, reuniam-se professores, sábios e lideranças, durante um final de semana numa mesma aldeia, com o objetivo de discutirem a respeito tanto da educação indígena como a respeito de como a escola pode vir a fortalecê-la. Nos meses de intervalo entre os grandes encontros, a partir das orientações dos anciões e diretamente sob a sua supervisão, os professores desenvolviam ações junto aos seus alunos. Nelas abordaram, preferencialmente fora da sala de aula, saberes indígenas ligados a âmbitos como alimentação, agricultura, caça, pesca, ervas medicinais, brinquedos e brincadeiras, narrativas tradicionais, histórias de vida dos anciões, preparação para o exercício das atividades de liderança, etc. ${ }^{13}$

Os grandes encontros contaram com a participação de membros externos às comunidades, tais como membros da equipe de formação da UFSC, servidores das instituições educativas da esfera estadual e servidores de outras instituições como a FUNAI, a SESAI, o Ministério Público Federal ou outras universidades, conforme solicitado, para cada encontro, por lideranças e professores. A participação dos técnicos e gerentes dos órgãos de gestão educativa, requerida muito enfaticamente pelas lideranças e professores indígenas para todos os encontros nos três contextos étnicos catarinenses (Guarani, Kaingang e Laklãnõ-Xokleng), não foi tão intensa e permanente quanto por eles demandado: a exigência era a sua participação em tempo completo. É por isso que lideranças e professores aproveitaram cada

12. A transcrição completa encontra-se disponível no capítulo 5 de Guerola (2017b), particularmente na seção 5.4.1, entre as páginas 249 e 256 . Notas biográficas dos enunciadores indígenas no dado em análise encontram-se entre as páginas 257 e 261. O registro audiovisual completo do diálogo encontra-se disponível em: < https://vimeo.com/202537651>, sob a senha "asiesc". Evito nomear explicitamente a instância institucional em questão para dificultar sua identificação e, destarte, o virtual constrangimento daqueles que a performativizam.

$13 \mathrm{O}$ material didático produzido a partir da sistematização dos registros dessas ações e das atividades pedagógicas para trabalho complementar em sala de aula elaboradas pelos professores intitula-se Ãg tõ Laklãnõ-Xokleng ãg jákle vãnhló zi kũ: ãg jóba mẽ óg jávãn kũ tõ óg ze jógpalag jã - Consciência Laklãnõ-Xokleng em ação: Jeitos de ensinar e aprender na Terra Indigena Laklãnõ e se encontra disponível em: < http://saberesindigenas.ufsc.br/livros/>. Acesso em: 27 set. 2018. 
um dos preciosos instantes em que tal participação se efetivou para colocarem esses gestores e técnicos na posição de interlocutores privilegiados e exporem para eles (em diferentes graus de formalidade, cordialidade e/ou agressividade) as suas reclamações e demandas, estabelecendo um diálogo com eles que, por vezes, se transformava em confronto. Tal diálogo (particularmente nas próprias terras indígenas e com a presença maciça ${ }^{14}$ de todos os envolvidos nos processos escolares de ensino-aprendizagem nas diferentes aldeias) era esperado, na maioria das ocasiões, desde longa data. Esse foi o caso da interação que analiso a seguir.

Nos excertos analisados da interação, participaram enquanto enunciadores e centros de transmissão de poder, incorporando o Povo Laklãnõ-Xokleng, o sábio/ ancião Sr. João Paté (que já ocupou em diversas ocasiões cargos de liderança, tanto política como religiosa, na TI), os professores (todos eles formados pela Licenciatura Intercultural Indígena do Sul da Mata Atlântica da UFSC) Copacãm Tschucambang (que já ocupou o cargo de cacique regional e desempenhou as funções de orientador de cultura na escola Laklãnõ ${ }^{15}$ ), Walderes Coctá Priprá (na época, no cargo de secretária da escola Vanhecu Patté) e Osias Tukun Paté (filho de João Paté e que também já assumiu funções como orientador de língua em escolas da TI ${ }^{16}$. Junto com eles, participou como enunciador a liderança Laklãnõ-Xokleng Setembrino Camlém, que exercia, à época do desenvolvimento da pesquisa, a função de Cacique Presidente da TI. Incorporando o Estado, participou em qualidade de enunciadora a professora Roberta ${ }^{17}$.

Para dar resposta à pergunta que pauta este trabalho, elenco a seguir e ilustro com exemplos as estratégias de construção de sentido para perpetuação/

14. Os grandes encontros da ASIE-SC reuniam, em média, entre 150 e 200 assistentes.

15. Há quatro escolas Laklãnõ-Xokleng em Santa Catarina, único estado com presença dos aproximadamente 2000 membros dessa etnia. Três delas se localizam na TI Ibirama Laklãnõ (escola Laklãnõ, escola Vanhecu Patté e escola Luzia Meiring) e uma na TI Rio dos Pardos, onde mora um número reduzido de famílias.

16. O primeiro concurso específico para professores indígenas na rede estadual de SC teve lugar em 2017. Até então (e, em grande medida, também até hoje), a totalidade de professores contratados nas escolas indígenas (com exceção de poucos professores efetivados em concursos não específicos) o eram em qualidade de $\mathrm{ACT}$ s, isto é, professores admitidos em caráter temporário. Pelo caráter temporário (e precário) do seu vínculo empregatício com o Estado, renovado (ou não) a cada início de ano letivo, muitos desses profissionais precisam se envolver em outras atividades econômicas para complementação de renda. Era o que o professor e liderança Marcondes Namblá, a quem é dedicado este texto, se dispunha a fazer (particularmente, vender picolé) na praia de Penha (SC), quando foi brutalmente assassinado a pauladas por um estranho (por 'motivo fútil', de acordo com a narrativa policial e midiática), na noite da virada de 2018.

17. No intuito de favorecer a preservação de anonimato e, com ela, a diminuição de riscos associados a constrangimento público e desavenças com terceiros, o centro de transmissão de poder do Estado é nomeado através de pseudônimo. Os enunciadores indígenas explicitaram o seu desejo de serem identificados nos textos de divulgação da pesquisa. 
transformação das relações de força dissimétricas entre, de um lado, os cinco centros de transmissão de poder Laklãnõ-Xokleng - e a instituição/(id)entidade que incorporam - e, de outro, o centro de transmissão de poder não indígena - e, igualmente, a instituição/(id)entidade por ela incorporada.

Do lado Laklãnõ-Xokleng, a primeira estratégia identificada consiste em representar a educação diferenciada enquanto direito ("Nós temo esse direito de ter uma educação diferenciada") e denunciar a sua vulneração ("O que que é diferente? Qual é a diferença da educação do índio com o povo lá de José Boiteux?", "Não tem diferença nenhuma! Pra mim não!", "Hoje meus filho tão educando os filho deles de outro tipo, de um outro povo") por parte do Estado ("o Estado não tá respeitando", "o Governo acha que já tem educação diferenciada. Não, não tem").

Refleti detidamente em trabalhos anteriores (GUEROLA, 2012; 2014; $\left.2017 a_{i} 2017 b\right)$ acerca da categoria direito no discurso indígena, particularmente no que diz respeito à educação escolar, assim como acerca da reconstrução intercultural (SOUSA SANTOS, 2010) desse direito em razão das necessidades e obrigações impostas às populações indígenas pela sua inserção compulsória no sistema civilizacional do capitalismo neoliberal contemporâneo. Por esse motivo, não me deterei aqui nessa categoria. Vale dizer que a remissão ao conceito de direito e a denúncia da sua vulneração por parte do Estado são estratégias indígenas de construção de sentido fundamentais Brasil afora para fins de transformação da perpétua dissimetria das relações de força que essas populações mantêm com o Estado.

A segunda estratégia Laklãnõ-Xokleng de construção de sentido consiste em contestar a espoliação que o Estado faz das "possibilidades intencionais da língua" (BAKHTIN, 2002, p. 97) ao sobrecarregar com suas próprias intenções palavras como educação indígena (diferenciada) e escola indígena. Dentro dessa estratégia, o prof. Copacãm Tschucambang aponta, por um lado, para o embate de intenções dentro da educação indígena ("A educação indígena ela tem duas visões"), embate esse que trava a sua materialização ("Então não tem como trabalhar"). Por outro lado, ao contrastar escola indígena e educação indígena diferenciada enfática e reiteradamente ("educação indígena diferenciada é uma coisa; escola indígena é outra situação", "Escola indígena, educação indígena: são duas coisa diferente uma da outra", "educação indígena diferenciada, escola indígena, outra coisa"), o prof. Copacãm aponta para a inadequação das intenções com que o Estado, na sua visão, está sobrecarregando essas palavras ("essa confusão, essas coisa que o Estado tá trocando").

As intenções do Estado em relação à escola indígena e à educação indígena diferenciada ainda se encontram distantes das intenções dos Laklãnõ-Xokleng porque o Estado, 
na visão destes, ainda as desconhece ou incompreende ("O Estado não sabe como que a gente quer", "O governo não tá entendendo", "uma palavra sem entender o que que é, uma palavra que ninguém tá entendendo"). É por isso que, embora a educação escolar diferenciada seja um direito constitucional dos indígenas desde 1988 e a responsabilidade de garantir esse direito caiba ao governo de Santa Catarina desde $1991^{18}$, os Laklãnõ-Xokleng cobram ainda hoje dos servidores do Estado, 30 anos depois, interesse ("O importante também é que o pessoal da Secretaria que trabalha com os povos indígenas, eles também tenham interesse em conhecer um pouco mais da cultura, da tradição, da língua") e compreensão ("O pessoal que tá trabalhando com educação indígena tem que conbecer a educação indígena", "O que governo tem que entender, quem lida com a educação, acho que tem que entender", "essas coisa que a gente tem que entender") para que esse direito possa se efetivar.

E qual é a intenção dos Laklãnõ-Xokleng por trás da educação diferenciada e da escola indígena? $\mathrm{O}$ que essas palavras representam para eles? A intenção dos LaklãnõXokleng por trás desses signos (e outros equivalentes no texto em análise, tais como "o diferente", "o diferenciado", "a verdadeira educação diferenciada", ou a "escola diferenciada") é a intenção dos anciões ("o que eles vão falar", "conforme a realidade e o pensamento deles", "como o mais velho quer", "como o ancião quer, como a pessoa idosa quer", "tudo isso que os anciões falaram"), intenção essa que diz respeito particularmente à ação dos corpos Laklãnõ-Xokleng em determinados espaços ("ir no mato conhecer a madeira, os animais, a forma de extrair mel").

Não obstante, a intenção dos centros de transmissão de poder do Estado por trás da educação indígena e da escola indígena, segundo os Laklãnõ-Xokleng, é apenas que as escolas se localizem dentro de áreas indígenas e incluam na sua grade curricular disciplinas específicas de língua e artes ("O fato de ter Língua Xokleng, Arte Xokleng, na escola, o Estado acha que os Xokleng, os Guarani, os Kaingang, no estado de Santa Catarina, o Governo acha que já tem educação diferenciada", "Às vezes o Estado, ou seja, a Secretaria de Educação do Estado, ela se foca em duas situações: a Língua Xokleng e a Artes Indígenas que foi inserida dentro da grade curricular", "Quando se fala educação indígena, o Estado tá entendendo que o fato de ter uma escola dentro da terra indígena, o fato de ter Artes Indígena, Língua Indígena, dentro da escola indígena, é escola diferenciada").

O sobrecarregamento desses signos com tais intenções é coerente com visões ortodoxas de políticas de educação bilíngue para preservação de línguas ameaçadas (cf. CALVET, 2007; D’ANGELIS, 2012; GUEROLA, 2015a, 2015b),

18. Cf. Decreto Nº 26, de 4 de fevereiro de 1991, da Presidência da República, que "dispõe sobre a Educação Indígena no Brasil", incluído em Magalhães (2005, p. 483). 
as quais, segundo Makoni e Pennycook (2006), são coerentes, por sua vez, com processos coloniais de violência epistêmica e invenção de línguas. Os processos de invenção de línguas e as políticas linguísticas a eles associadas têm consequências "particularmente insidiosas" para os povos indígenas (MAKONI, PENNYCOOK, 2006, p. 23), como, por exemplo, no caso que nos ocupa, que o Estado consiga, através delas, restringir as ações dos corpos de professores e estudantes LaklãnõXokleng aos limites espaciais da sala de aula ("O professor em sala de aula, quando o professor tira os alunos, por exemplo, a uma roda de conversa lá fora da sala de aula, já muitas vezes acontece que a gerência não aceita porque isso não é considerado aula", "a gente enfrentou alguns problemas relacionados a isso. A gente tirava os alunos, 'Não, isso aí não é a aula", "Não considera como aula").

A restrição das ações de estudantes e professores aos limites da sala de aula é contrária, porém, às intenções que norteiam a educação Laklãnõ-Xokleng (dentre as quais "ir no mato conhecer a madeira, os animais, a forma de extrair mel") e a educação indígena de modo geral ("Assim, professora: A educação indígena ela não funciona em quatro paredes. Ela vai muito além de quatro paredes"). Essa restrição se mostra particularmente grave se relembrarmos que a mobilidade é uma das características mais significativas do modo de vida Laklãnõ-Xokleng (cf. LAVINA, 1994; NOELLI, 2000; LOCH, 2004; WITTMANN, 2005).

Confirmam-se neste ponto dois postulados foucaultianos: 1) a centralidade do corpo, enquanto realidade biopolítica, nas relações e mecanismos de poder (FOUCAULT, 1979); e 2) a associação entre "privilégios do saber" e "efeitos de poder" (FOUCAULT, 1995, p. 235) que se evidencia na desqualificação e deslegitimação de práticas de ensino-aprendizagem Laklãnõ-Xokleng que não seguem as regras do gênero textual aula determinadas pelo Estado, dentre as quais, ocorrer "entre quatro paredes" ("isso não é considerado aula", "Não, isso aí não é a aula", "Não considera como aula").

Perante essas duas primeiras estratégias de construção de sentido dos Laklãnõ-Xokleng - por um lado, representar a educação diferenciada enquanto direito e denunciar a sua vulneração por parte do Estado e, por outro, contestar e circunstanciar a forma em que o Estado espolia as possibilidades intencionais da língua através da espoliação de signos como educação indígena diferenciada ou escola indígena e de gêneros textuais como o gênero aula -, o Estado responde com uma estratégia de concordância com atenuações. Vejamos:

A concordância explícita ("realmente, concordo com vocês") que o centro de transmissão de poder que incorpora o Estado faz em relação à inadequação da escola Laklãnõ-Xokleng ("ela não funciona", "não pode ser dessa maneira", "não 
é o ideal") é atenuada em relação ao contraste entre educação diferenciada e escola diferenciada: enquanto, num primeiro momento, o uso de anáforas ("Isso que você fala é muito importante", "essas coisas realmente não casam") sugere concordância em relação a esse contraste, num segundo momento, há uma mudança nos referentes dessas anáforas no intuito de transferir o contraste para os signos educação indígena e sistema escolar.

Essa atenuação é significativa por três motivos. Em primeiro lugar, porque, por um lado, as "ações burocráticas" do sistema escolar são, para a professora Roberta, o impedimento das "ações diferenciadas dentro da escola". Afinal, tanto para ela como para a instituição que incorpora e representa, independentemente de serem indígenas e/ou diferenciadas, as escolas dos Laklãnõ-Xokleng se inserem num "sistema comum" ("A escola de vocês tá num sistema comum a todas as outras escolas") pautado por regulamentações e determinações cuja observação e cumprimento independe de características específicas ("existem coisas que precisam serem pontuais"). Em segundo lugar, porque, por outro lado, se essas ações burocráticas próprias do sistema escolar impedem a diferenciação da escola indígena é, segundo a professora Roberta, por causa do desconhecimento desse sistema por parte dos indígenas ("A cultura de vocês não entende esse sistema burocrático [...] e aí acaba acontecendo essa falha"), o que corrobora novamente o fato das lutas em torno do poder dizerem respeito "aos efeitos de poder relacionados ao saber, à competência e à qualificação" (FOUCAULT, 1995, p. 235). Afinal, seria a pretensa desqualificação ou incompetência dos indígenas (ou, antes, da sua cultura), segundo o Estado, a causa do problema.

O terceiro motivo pelo qual aponto para as atenuações dessa estratégia de concordância é ela acarretar a acusação, por parte da profa. Roberta, de que a escola Laklãnõ-Xokleng descumpre regulamentações e determinações do "sistema comum" em que se insere ("O que tá aqui dentro não está indo de acordo com o Estado"), acusação que vem acompanhada de uma ameaça, também atenuada ("se eu não presto contas do dinheiro que entra aqui, vocês serão prejudicados, porque 0 dinheiro não virá mais"). Essa sub-estratégia de ameaça atenuada vinculada ao dinheiro é particularmente significativa num contexto economicamente sensível onde a alimentação das crianças depende em grande medida das refeições que fazem na escola, e onde o sustento financeiro de um número significativo de famílias depende dos salários advindos da escola (cf. WIIK, 2010).

A estratégia de concordância atenuada é empregada por todos os contendentes na hora de proporem soluções ao conflito. Assim, se há uma concordância em relação ao papel central que o sistema desempenha no mesmo ("'a questão que a 
gente se encontra hoje é o sistema', 'o sistema', 'o sistema'"), os Laklãnõ-Xokleng atenuam essa concordância negando o desconhecimento de que o Estado lhes acusa ("A gente entende perfeitamente a questão do sistema"), reivindicando que a solução é que suas intenções prevaleçam ("É o sistema que tem que se adequar à educação indígena, não a educação indígena se adequar ao sistema [...] essa questão que a gente tem que brigar") e enunciando assertivamente que projetos que façam prevalecer tais intenções serão executados independentemente da aprovação ou não do Estado ("vai se preparando que esse projeto vai acontecer", "esse aqui é um projeto que a gente vai executar"). Por sua vez, o Estado enuncia a sua concordância ("É...", "Isso"), porém redirecionando-a novamente para outros referentes ("Isso, vamos dialogar, vamos estabelecer metas", "não vamo falar brigar, vamo dizer trabalhar").

Há concordância também de ambos os lados em que a solução passa por enunciar discursos em gêneros específicos. Assim, para os Laklãnõ-Xokleng, é necessário que as suas intenções por trás da educação escolar diferenciada sejam enunciadas através do gênero discursivo projeto político pedagógico ("Projeto PolíticoPedagógico, é nesse daí que a gente vai colocar [...] como que nós queremo [...] Nós vamo registrar tudo isso e incluir isso no PPP, que escola que nós queremo"). Apenas a enunciação das suas intenções através desse gênero textual lhes garantirá o poder de coerção necessário para obrigar o Estado a respeitar uma educação escolar pautada nelas ("Aí sim o Estado é obrigado a respeitar da forma que a gente quer educar os nossos filhos", "A partir do momento que nós criar, aí nós vamo obrigar o Estado", "Aí sim, nós tamo com subsídio pra exigir do Estado"), inclusive no âmbito judicial ("Se não quer respeitar, podemo abrir uma ação contra o Estado", "Não quer respeitar? Abre-se uma ação contra o Estado através do Ministério Publico"). Note-se também que, para os Laklãnõ-Xokleng, é devido a não terem enunciado ainda suas intenções através desse gênero que hoje carecem de capacidade de coerção nesse sentido ("Agora nós não temos como, com base no quê, exigir do Estado pra uma educação diferenciada").

Já o centro de transmissão de poder que incorpora o Estado representa a enunciação através da modalidade escrita de modo geral ("onde é que nós vamos buscar caminhos para resolver isso? [...] produzindo documentos [...] registros") como forma das intenções dos Laklãnõ-Xokleng por trás da educação indígena diferenciada e da escola indígena não apenas ganharem valor de coerção, mas o próprio status de legalidade ("legalizar' essa nova forma de escola"). Cabe aqui apontar que, do mesmo jeito que a estratégia de remeter ao conceito de direito e denunciar o Estado por vulnerálo foi apontada páginas atrás como uma das principais estratégias dos indígenas Brasil afora para fins de transformação da perpétua dissimetria das relações de força que mantêm com o Estado, a estratégia de permanente remissão à enunciação de 
textos escritos (em gêneros textuais específicos ou não) pode ser considerada uma das principais estratégias do Estado, nas suas diferentes ramificações e esferas, para perpetuar relações de força dissimétricas com coletivos ou indivíduos que, em alguma medida, dependem dele - estratégia essa que é notadamente visível no universo da educação escolar indígena (GUEROLA, 2012; 2017b).

Assim sendo, o centro de transmissão de poder que incorpora o Estado remete os Laklãnõ-Xokleng - com base em documentos que não dizem respeito particularmente à educação escolar indígena e sim à escola regular de modo geral ("as diretrizes de 2012", "a proposta das novas diretrizes curriculares para ensino médio") - à enunciação das suas intenções através do gênero projeto ("Hoje a educação não indígena, ou indígena, pra mim ela trabalha, ela pode trabalhar, ela é amparada por lei, por projetos"), sendo que apenas a observação e cumprimento das regras de conteúdo e estrutura desse gênero dará aos projetos escolares LaklãnõXokleng eficácia e poder de coerção legal ("se eu tenho um projeto de pesquisa e eu quiser levar esse meu aluno a conhecer, não bá impedimento legal pra isso, desde que os professores aprendam a elaborar uma pesquisa com seus objetivos, estratégias e metodologias"). Privilégios do saber quanto a gêneros do discurso específicos fundamentam, novamente, a desqualificação e deslegitimação ("ensinar por ensinar") de práticas de ensino-aprendizagem não pautadas neles.

Acabei de elencar e analisar as estratégias de construção de sentido empregadas no dado em análise pelos centros de transmissão de poder do Povo Laklãnõ-Xokleng e do Estado para apontarem o problema da não diferenciação da escola indígena, assim como as suas causas e possíveis soluções. Analiso a seguir duas estratégias transversais àquelas, relacionadas à representação que os centros de transmissão de poder em análise fazem de si no que diz respeito à sua capacidade de transformação dentro de instituições que incorporam discursivamente como (id) entidades.

A estratégia dos Laklãnõ-Xokleng consiste em representar-se enquanto agentes propositados que podem "intervir no mundo [...] com o efeito de influenciar um processo específico" e "fazer a diferença" (GIDDENS, 1984, p. 14) ou, nas palavras de Freire (1967), enquanto seres eminentemente interferidores que dominam a sua realidade e fazem cultura. É em decorrência dessa representação que fazem de si que afirmo neste trabalho que os centros de transmissão de poder Laklãnõ-Xokleng incorporam, enquanto instituição-(id)entidade, uma cultura.

Como desenvolvem os Laklãnõ-Xokleng essa estratégia? Por um lado, representando-se enquanto agentes propositados que não só se atribuem desejos como também a responsabilidade por materializá-los ("é nós que temo que construir 
do jeito que a gente quer [...] é nós que temo que construir", "e nesse daí que a gente vai colocar, mas tudo a partir desse trabalho que nós vamo fazer. Depois nós vamo pensar, construir esse PPP, como que nós queremo, mas tudo depois que a gente registrar tudo isso que vocês [anciões] contarem pra nós. Nós vamo registrar tudo isso e incluir isso no PPP, que escola que nós queremo. Aí sim o Estado é obrigado a respeitar da forma que a gente quer educar os nossos filhos. Se não quer respeitar, podemo abrir uma ação contra o Estado. [...] A partir do momento que nós criar, aí nós vamo obrigar o Estado"). Por outro lado, os Laklãnõ-Xokleng se representam enquanto agentes resolutos cujas determinações se mantêm firmes, a despeito de circunstâncias adversas, graças ao próprio esforço ("São situações que... esse aqui é um projeto que a gente vai executar, vamos criar o material", "Então, Roberta [...] já vai se preparando que esse projeto vai acontecer", "Nós temos professores aqui que, quando foram fazer curso na universidade, encontraram [...] dificuldade pelo Estado. Mas com os seus próprios esforço, chegaram a concluir o curso", "se tiver só o esforço da comunidade e dos professor e não tiver o apoio do Estado...")

Essa estratégia é desenvolvida pelos Laklãnõ-Xokleng, simultaneamente, ao se representarem enquanto agentes ativos em movimento, representação que é condizente com o apontado páginas atrás em relação à mobilidade constituir uma das características definidoras da cultura Laklãnõ-Xokleng, assim como com a visão de Freire (1967) de que os seres humanos fazem cultura temporalizando espaços geográficos. Já do Estado e/ou das suas ramificações, os Laklãnõ-Xokleng constroem uma representação completamente contrária, enquanto agentes passivos sem movimento. Isso pode ser notado na construção de enunciados através de recursos linguísticos que indicam direcionalidade para representar ações dos Laklãnõ-Xokleng ("professores [...] que, quando foram fazer curso na universidade [...] chegaram a concluir o curso", "A gente já bateu... [...] a gente enfrentou alguns problemas relacionados a isso", "lá na frente vou bater de frente com o sistema"), enquanto se recorre, nos enunciados em que representam ações do Estado, a recursos linguísticos que sugerem estatismo, imobilidade ou passividade ("encontraram dificuldade pelo Estado", "o pessoal que tá lá dentro que é responsável pela educação indígena nunca chegou lá, por exemplo, na escola Vanhecu Patté. Alguém já foi lá [...]?", "Nunca foi alguém lá sentar com os professores para conversar relacionado a isso", "não adianta nós fazer um projeto aqui se nós encontrar a barreira com o Estado").

A estratégia do centro de transmissão de poder que incorpora o Estado consiste em representar-se enquanto uma identidade institucional que, ao contrário dos Laklãnõ-Xokleng, carece de capacidade para "intervir no mundo [...] com o efeito de influenciar" e "fazer a diferença" (GIDDENS, 1984, p. 14). Como vimos, 
essa representação é própria de homens e mulheres acomodados e ajustados que, abdicando da consciência da sua capacidade de transformação, se dizem impotentes e paralisados perante catástrofes (FREIRE, 1967).

É em decorrência dessa representação que afirmo neste trabalho que a profa. Roberta incorpora, enquanto instituição-(id)entidade, um estado. É a respeito de estados que cabe falar mais propriamente de incorporação, pois é nesses casos que a instituição é representada enquanto uma entidade com existência própria. Já na incorporação de culturas a noção de performatividade das instituições fica mais manifesta, uma vez que, como vimos anteriormente, aqueles que as assumem e performativizam identitariamente são mais conscientes do seu caráter interferidor e da sua capacidade de transformação nelas, donde o termo incorporação poder resultar menos adequado. A "passividade própria" (FOUCAULT, 1979, p. 46) com que a profa. Roberta se representa pode significar, ademais, como foi discutido na fundamentação teórica, insubmissão em relação ao exercício de poder por parte dos Laklãnõ-Xokleng contra a instituição que incorpora e representa.

A professora Roberta desenvolve a sua estratégia identitária de construção de sentido através de enunciações na primeira pessoa do plural nas quais se exclui enquanto indivíduo singular ("Nós temos que mudar isso. Quem que vai mudar isso? Não é Roberta gerente, mas é em todo o sistema. Eu não tenho essa competência pra isso", "Mas o que vamos fazer? A Roberta, enquanto gerente, executa as políticas públicas que o governo tem. Eu tenho que me preocupar que realmente essas políticas estejam sendo executadas. Então o que nós queremos mudar de políticas públicas para educação indígena?", "Vamos construir. Mas não é a Roberta que vai ter esse poder de dizer que nós vamo mudar isso. Não sonhem com isso, nem pensem que eu não entendo que está errado. Eu entendo que está errado, mas eu não posso fazer diferente.")

Eis aqui que a noção de incorporação de estados enquanto (id)entidades, assim como a constatação de processos de acomodação/ajustamento, ganham o seu sentido e materialização plenos: note-se as referências que a Roberta faz a si própria através de uma primeira e, inclusive, terceira pessoas que, quando imbuídas na sua função, apenas executam as determinações da instituição/(id)entidade, convictas da sua impossibilidade ("eu não tenbo competência pra isso", "não é a Roberta que vai ter esse poder [...] Não sonhem com isso", "eu não posso fazer diferente") mesmo perante catástrofes ("Eu entendo que está errado").

As estratégias de construção de sentido do Povo Laklãnõ-Xokleng e do Estado identificadas no dado cuja análise aqui encerro poderão ser identificadas em outras pesquisas de natureza semelhante, em outros contextos institucionais, étnicos e geográficos Brasil afora. Elas são de natureza linguística e de cunho 
ideológico e político, são intencionais e sua performatização, como outras pesquisas também poderão mostrar, se repete sistematicamente. Elas constituem em si mesmas políticas linguísticas, em estreita relação com políticas de identidade, etnograficamente constatáveis.

\section{CONSIDERAÇÕES FINAIS}

Busquei neste trabalho identificar e ilustrar, com base num texto gerado e analisado etnograficamente, estratégias de construção de sentido para transformação ou perpetuação de relações de força dissimétricas que duas instituições (o Povo Laklãnõ-Xokleng e o Estado de Santa Catarina) e os seus centros de transmissão de poder mantêm entre si. Por parte dos Laklãnõ-Xokleng, as estratégias foram: 1) representar a educação escolar diferenciada enquanto direito e denunciar o Estado por vulnerá-lo; 2) contestar e circunstanciar a espoliação por parte do Estado das possibilidades intencionais da língua em palavras como educação indígena diferenciada e escola indígena e formas como o gênero textual aula; 3) Remeter à enunciação através de gêneros textuais específicos para que enunciados que explicitem as suas intenções por trás da escola indígena e da educação diferenciada tenham eficácia, efeitos e poder de coerção; e 4) representar-se enquanto agentes com capacidade de transformação que incorporam (ou, antes, fazem) uma cultura. Por parte do centro de transmissão de poder do Estado, as estratégias foram: 1) concordar com atenuações; 2) remeter à enunciação através de gêneros específicos e ao cumprimento das regras quanto à estrutura e conteúdo possível dos mesmos; e 3) representar-se enquanto agente sem capacidade de transformação que incorpora um estado.

Abordei, assim, políticas linguísticas em sua relação com políticas de identidade associadas a uma questão que aflige as populações indígenas na contemporaneidade (as relações dissimétricas de poder que mantêm com o Estado e os seus servidores, particularmente no contexto da educação escolar), estudando estratégias por elas empregadas para fazerem frente às posições de subalternidade em que são colocadas nessas relações.

Estudos vindouros (para cujo desenvolvimento convido pesquisadores da Linguística Aplicada e de outras áreas como a Pedagogia, a Antropologia, a Sociologia Política ou a História) poderão corroborar ou refutar que as estratégias de construção de sentido aqui elencadas e ilustradas, pelo seu marcado cunho político e ideológico e pela intencionalidade e sistematicidade que as permeiam, constituem políticas linguísticas e de identidade, próprias de estados ou de culturas, para perpetuação ou transformação de relações de poder dissimétricas. Apenas a geração e análise 
etnográfica de dados em outros contextos - tanto no que diz respeito a povos indígenas diferentes (e outras populações da periferia do capitalismo neoliberal) como a diferentes ramificações e instâncias do Estado brasileiro -, vinculadas a uma discussão teórica aprofundada quanto ao que caracteriza efetivamente esse tipo de políticas, poderão fornecer insumos e caminhos para se responder à questão.

Trabalhos dessa índole, que falem publicamente sobre focos particulares de poder em torno dos quais se desenvolvem lutas, estratégias e políticas, constituirão parte dessas lutas - afirmava Foucault (1979) - pontapés iniciais para se inverter o poder. Vamos, pois, à luta!

\section{REFERÊNCIAS}

BAKHTIN, M. (1997). Estética da criação verbal. São Paulo: Martins Fontes.

BAKHTIN, M. (2002). Questões de Literatura e de Estética: a teoria do romance. São Paulo: Hucitec.

BAKHTIN, M. (2006). Marxismo e filosofia da linguagem: problemas fundamentais do método sociológico na ciência da linguagem. São Paulo: Hucitec.

BRASIL. (1988). Constituição da República Federativa do Brasil: promulgada em 5 de outubro de 1988. Disponível em: <http://www.planalto.gov.br/ccivil_03/constituicao/ constituicao.htm >. Acesso em: 05 out. 2018.

BRIGHENTI, C. A.; NÖTZOLD, A. L. V. (2010). Educação guarani e educação escolar: Desafios da experiência mbya e nhandeva. Cadernos do LEME, v. 2, n. 2, pp. 22-40.

BUTLER, J. (2010). Performative Agency. Journal of Cultural Economy, v. 3, n. 2, pp. 147-161.

CALVET, L.-J. (2007). As políticas linguísticas. São Paulo: Parábola Ed, IPOL.

CAVALCANTI, M. C. (1999). Estudos sobre educação bilíngue e escolarização em contextos de minorias linguísticas no Brasil. D.E.L.T.A., v. 15, n. Especial, pp. $385-$ 417.

CLIFFORD, J.; MARCUS, G. E. (orgs.). (1986). Writing Culture: The Poetics and Politics of Ethnography. Berkeley/Los Angeles: University of California Press.

D’ANGELIS, W. D. R. (2012). Aprisionando sonhos: a educação escolar indígena no Brasil. Campinas: Curt Nimuendajú. 
DAVIES, C. A. (1999). Reflexive Ethnograpby: A guide to researching selves and others. Londres/Nova Iorque: Routledge.

ERICKSON, F. (1990). Qualitative Methods. In: Linn, R.; Erickson, F. (orgs.). Quantitative Methods Qualitative Methods: A Project of the American Educational Research Association. Londres/Nova Iorque: Macmillan Publishing Company.

FOUCAULT, M. (2004a). A ética do cuidado de si como prática da liberdade. In:

Ditos \& Escritos V-Ética, Sexualidade, Política. Rio de Janeiro: Forense Universitária. pp. 265-287.

FOUCAULT, M. (2004b). A ordem do discurso. [s.1.]: Sabotagem.

FOUCAULT, M. (1995). O sujeito e o poder. In: Rabinow, P.; Dreyfus, H. (orgs.). Michel Foucault: Uma trajetória filosófica - para além do estruturalismo e da bermenêutica. Rio de Janeiro: Universitária. pp. 231-252.

FOUCAULT, M. (1979). Microfísica do poder. Organização, introdução e revisão técnica de Roberto Machado. [s.1.]: Sabotagem.

FREIRE, P. (1989). A importância do ato de ler: em três artigos que se completam. São Paulo: Autores Associados/Cortez.

FREIRE, P. (1967). Educação como prática da liberdade. Rio de Janeiro: Paz e Terra.

GUEROLA, C. M. (2017a). "Os alunos teriam que estudar para poder comprar comida": A escola guarani como necessidade, obrigação e direito. Revista Brasileira de Educação, v. 22, n. 71 , pp. $1-25$.

GUEROLA, C. M. (2017b). "Se nós não fosse guerreiro, nós não existia mais aqui": Ensino-aprendizagem de linguas para fortalecimento da luta guarani, kaingang e laklãnõ-xokleng. Tese de doutorado em Linguística. Centro de Comunicação e Expressão, Universidade Federal de Santa Catarina, Florianópolis.

GUEROLA, C. M. (2015a). A disciplinarização letrada das línguas indígenas no Sul do Brasil: uma abordagem discursiva. Estudos Linguísticos, v. 44, n. 2, pp. 559-573.

GUEROLA, C. M. (2015b). Proporcionar aos índios a valorização das suas línguas?! Problemas discursivos na diferenciação da escola indígena. Revista Brasileira de Linguística Aplicada, v. 15, n. 3, pp. 779-807. 
GUEROLA, C. M. (2014). A reconstrução intercultural dos direitos humanos linguísticos escolares guarani: horizontes sociais e letramento. Trabalbos em Linguística Aplicada, v. 53 , n. 1 , pp. 225-241.

GUEROLA, C. M. (2012). "Às vezes tem pessoas que não querem nem ouvir, que não dão direito de falar pro indígena": a reconstrução intercultural dos direitos humanos linguísticos na escola Itaty da aldeia guarani do Morro dos Cavalos. Dissertação de Mestrado em Linguística. Centro de Comunicação e Expressão, Universidade Federal de Santa Catarina, Florianópolis.

GIDDENS, A. (1984). The Constitution of Society: Outline of the Theory of Structuration. Berkeley, CA: University of California Press.

HARVEY, D. (1996). Justice, Nature and the Geograpby of Difference. Oxford: Blackwell.

HEATH, S. B.; STREET, B. (2008). On etbnograpby: approaches to language and literacy research. Nova Iorque: Teachers College Press.

HYMES, D. (1996). Ethnograpby, Linguistics, Narrative Inequality: Toward an Understanding of Voice. Bristol/Londres: Taylor \& Francis.

KOCH, I. G. V. (2011). Desvendando os segredos do texto. São Paulo: Cortez.

LAVINA, R. (1994). Os Xokleng de Santa Catarina: uma etnobistória e sugestões para os arqueólogos. Dissertação de Mestrado em História. Universidade do Vale do Rio dos Sinos UNISINOS, São Leopoldo/RS.

LOCH, S. (2004). Arquiteturas xoklengs contemporâneas: uma introdução à antropologia do espaço na Terra Indígena de Ibirama. Dissertação de Mestrado em Antropologia Social. Centro de Filosofia e Ciências Humanas. Universidade Federal de Santa Catarina, Florianópolis.

MAGALHÃES, E. D. (org.). (2005). Legislação Indigenista Brasileira e normas correlatas. Brasília: FUNAI/CGDOC.

MAHER, T. J. M. (1998). Sendo índio em português. In: Signorini, I. (org.). Língua(gem) e identidade: elementos para uma discussão no campo aplicado. Campinas, SP: Mercado das Letras. pp. 115-138.

MAKONI, S.; PENNYCOOK, A. (2006). Disinventing and Reconstituting Languages. In: (orgs.). Disinventing and Reconstituting Languages. Clevedon: Multilingual Matters. pp. 1-41. 
NOELLI, F. S. (2000). A ocupação humana na região sul do Brasil: Arqueologia, debates e perspectivas 1872-2000. Revista USP, n. 44, pp. 218-269.

SANTOS, S. C. D. (1997). Os indios Xokleng: memoria visual. Florianópolis/Itajaí: Ed. da UFSC/ Ed. da UNIVALI.

SANTOS, S. C. D. (1987). A barragem de Ibirama e os índios. Geosul, v. 2, n. 4, pp. 42-47.

SANTOS, S. C. D. (1978). O bomem índio sobrevivente do sul; antropologia visual. Florianópolis/ Porto Alegre/Caxias do Sul: Universidade Federal de Santa Catarina/Departamento de Assuntos Culturais - MEC/Associação Nacional de Apoio ao Índio/Universidade de Caxias do Sul/Escola Superior de Teologia São Lourenço de Brindes/Editora Garatuja.

SOUSA SANTOS, B. D. (2010). Descolonizar el saber, reinventar el poder. Montevideu: Trilce.

SOUZA, L. M. T. M. D. (2009). Relatório sobre Educação Indígena Diferenciada, Intercultural e Bilíngue no Brasil. In: López, L. E.; Hanemann, U. (orgs.). Alfabetización y multiculturalidad: Miradas desde América Latina. Guatemala: UIL-UNESCO, PACEGTZ. pp. 99-128.

VAN MAANEN, J. (1988). Tales of the field. On writing ethnograpby. Chicago: The University of Chicago Press.

WIIK, F. B. (2010). "Somos índios crentes": dialéticas do contato, alteridade e mediação cultural entre os Xokleng (Jê) de Santa Catarina. Tellus, v. 10, n. 19, pp. 11-51.

WIIK, F. B. . (1998). Doenças e Transformação Sóciocultural entre os Índios Xokleng: epidemias, corporalidade e práxis entre os índios Xokleng do sul do Brasil. Revista de Divulgação Cultural, v. 20, n. 64, pp. 59-67.

WITTMANN, L. T. (2005). Atos do contato: Histórias do povo indígena Xokleng no Vale do Itajaí/SC (1850-1926). Dissertação de Mestrado em História. UNICAMP, Campinas/SP.

Recebido: 6/10/2018

Aceito: 19/10/2018 